\title{
A obra de Elomar Figueira Mello: contexto e estilo além do popular e do erudito
}

\author{
Eduardo de Carvalho Ribeiro (UFMG, Belo Horizonte, MG) \\ ribeiro1685@gmail.com
}

\begin{abstract}
Resumo: Discussão sobre os processos composicionais na obra de Elomar Figueira Mello, considerada neste artigo em duas vertentes: a regionalista e popular (presente no seu cancioneiro) e a erudita (representada principalmente por suas óperas), que integram estilos diversos como a cantoria nordestina, o estilo flamenco, a seresta, o tango, o hinário cristão e a música erudita tradicional. Essa integração produz contextos harmônicos com mesclas de modalismo e tonalismo, assim como um fraseado complexo derivado principalmente do uso do dialeto regional no sul da Bahia. 0 estilo de Elomar revela alguns dos "elos perdidos" na formação da música brasileira através de sua admirável hibridação de estilos e técnicas diversas.
\end{abstract}

Palavras-chave: hibridismo na música de Elomar; tonalismo, modalismo e cromatismo na música brasileira; dialetos e música popular.

\section{Elomar Figueira Mello's music: context and style beyond popular and classical}

Abstract: Discussion about the compositional processes in the work of Elomar Figueira Mello, here considered in two ways: regionalist and popular (as found in his cancioneiro) and classical (represented mainly by his operas). His work integrates several styles such as the "cantoria nordestina" (Brazilian northeastern way of singing), the flamenco style, the "seresta", the "tango", Christian anthems e and the classical music. This integration produces harmonic contexts with blends of modalism and tonalism and complex phrase forms derived mainly from the regional dialects from the south of Bahia. The style of Elomar reveals some of the "lost links" in the Brazilian music formation through the admirable hybridism of several styles and technics.

Keywords: hybridism in the music of Elomar; tonalism, modalism and chromaticism in Brazilian music; dialects and popular music.

\section{1- Introdução}

Elomar Figueira Mello é artista conhecido no Brasil desde a década de 1970, como compositor, cantor e violonista. É conhecido pelo público principalmente pelas canções do cancioneiro ${ }^{1}$, disponiveis em gravações comerciais. Uma seleção de grande parte de suas canções (em partitura para canto e violão), recentemente publicada em cadernos de partituras sob o título Elomar: cancioneiro ${ }^{2}$ representa um importante marco para o estudo e divulgação de sua obra. 0 universo poético e musical do cancioneiro já é suficiente para que Elomar seja considerado um músico impar pela sua originalidade e brasilidade incontestáveis, porém, pouco conhecida é sua obra considerada erudita: óperas, antífonas, concertos e sinfonias.
As áreas acadêmicas da linguística e literatura demonstram grande interesse pela obra literária e poética de Elomar e existem referências a aproximadamente quarenta trabalhos acadêmicos entre monografias, dissertações, teses e livros que tratam da poesia de suas canções e libretos e da riqueza linguística do dialeto por ele utilizado.

A obra de Elomar, no entanto, ainda carece de pesquisadores da área musicológica, interessados em investigar o rico cabedal musical e cultural encontrado em suas composições. Até a presente data registramse apenas dois trabalhos acadêmicos do ponto de vista musicológico ${ }^{3}$ sobre a obra de Elomar Figueira Mello. 
A música de Elomar apresenta-se em linguagem complexa e de difícil compreensão. São comuns audácias cromáticas, surpresas harmônicas e melodias sinuosas estruturadas em um fraseado nem sempre convencional, traços presentes em suas canções e também nas óperas de sua autoria. Alguns trechos de canções e árias serão úteis para exemplificar alguns procedimentos composicionais característicos de seu estilo.
A Cantiga do Estradar (Ex.1) faz parte do cancioneiro. Seu prelúdio instrumental (originalmente escrito para violão) é estruturado em frases assimétricas e harmonicamente ambíguas. Um pedal na voz interna sobre a nota Lá sustenta a longa frase assimétrica e modal nos c.1-13 $(5+4+3)$. A frase atinge uma cadência tonal em Lá menor e se expande nessa tonalidade em uma nova frase nos c.14-21 (3+5). Nos c.22-25, uma passagem na tônica
Cantiga do Estradar

"Antífona"
Elomar Figueira Mello
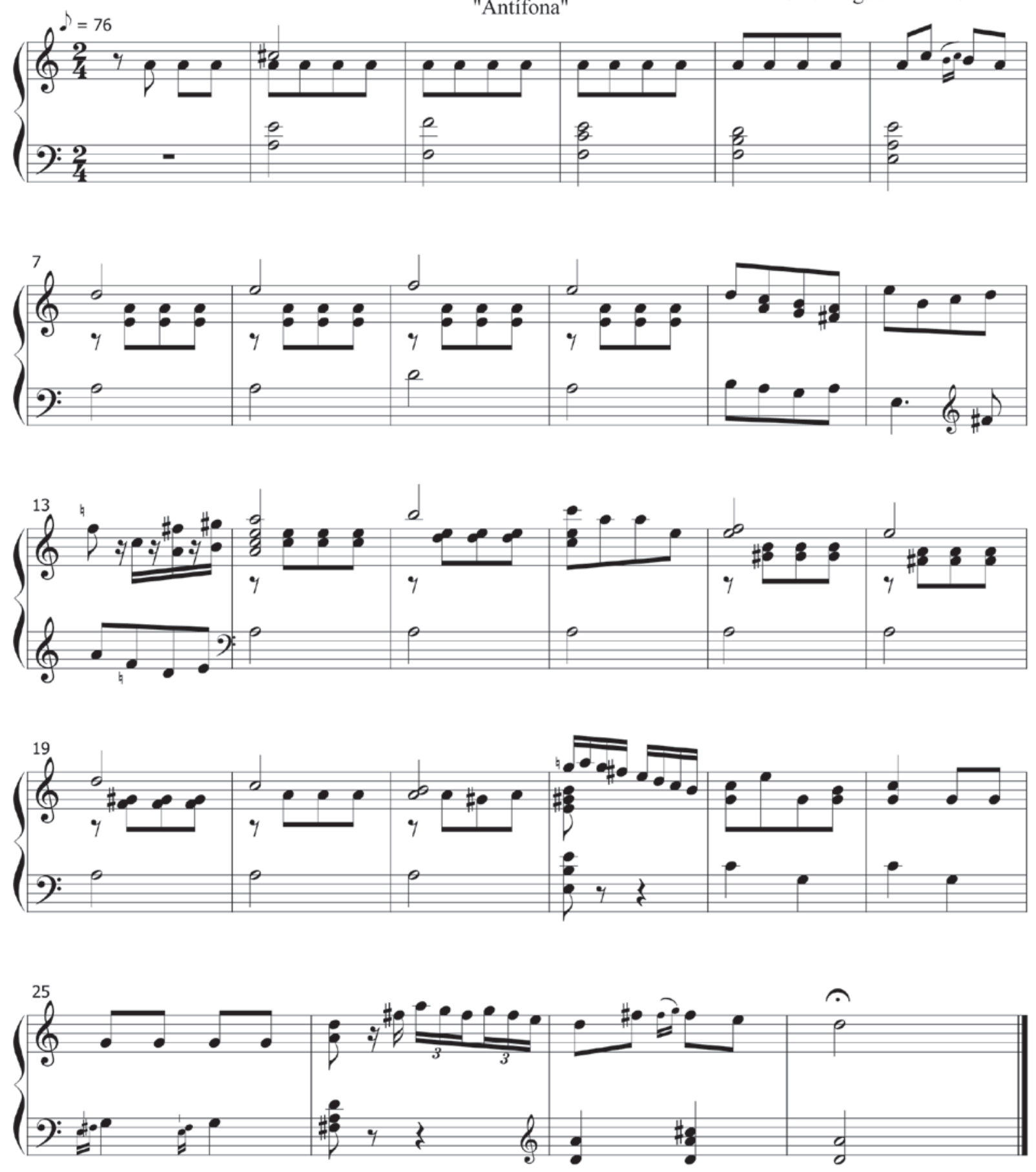

Transcrição: Eduardo Ribeiro

Ex.1 - Cantiga do Estradar de Elomar Figueira Mello (Elomar: cancioneiro, Caderno n.6). 
relativa (Dó Maior lídio) realiza uma cadência na região da subdominante (c.26-27) e resolve em Ré Maior (2+1). No c.22, o acorde dominante de Lá menor apresenta a dissonância Sol\# / Sol natural, sugerindo um breve contexto bitonal. A seção cantada oferece um elaborado desdobramento desse discurso.

Estrela Maga dos Ciganos (Ex.2) também faz parte do cancioneiro e mostra outro exemplo de mescla modaltonal. A frase inicial do prelúdio instrumental (original para violão) sugere o estabelecimento da tonalidade de Lá Maior nos c.1-2. Nos c.3-9, a sequência em Lá menor natural (modo eólio) atua como o homônimo. Uma surpreendente passagem nos c.10-13 inicia-se com o acorde de Dó menor (homônimo da tônica relativa de Lá menor). As falsas relações cromáticas nessa frase levam ao estabelecimento da tonalidade de Dó\# menor na cadência conclusiva do trecho, nos c.14-17. 0 fraseado irregular contribui para a instabilidade dinâmica dessa passagem.

A Cena de Espancamento na Paulista (original para barítono solista e orquestra) da ópera 0 Retirante (Ex.3) mostra a riqueza do estilo elomariano em sua linguagem musical a serviço do drama e da tragédia. 0 personagem "Zezin", um adolescente nordestino, sobrevive miseravelmente pelas ruas de São Paulo. Ao participar de um furto, é pego pela polícia e espancado até a morte por um guarda. Nesse trecho, quase sem forças, ensanguentado e delirante, "Zezin" sente seu espírito viajar ao passado de sua infância na terra natal: vê sua casa, o chiqueiro, o gado, seu avô e seu pai. 0 trecho é uma valsa em estilo "caixinha de música"
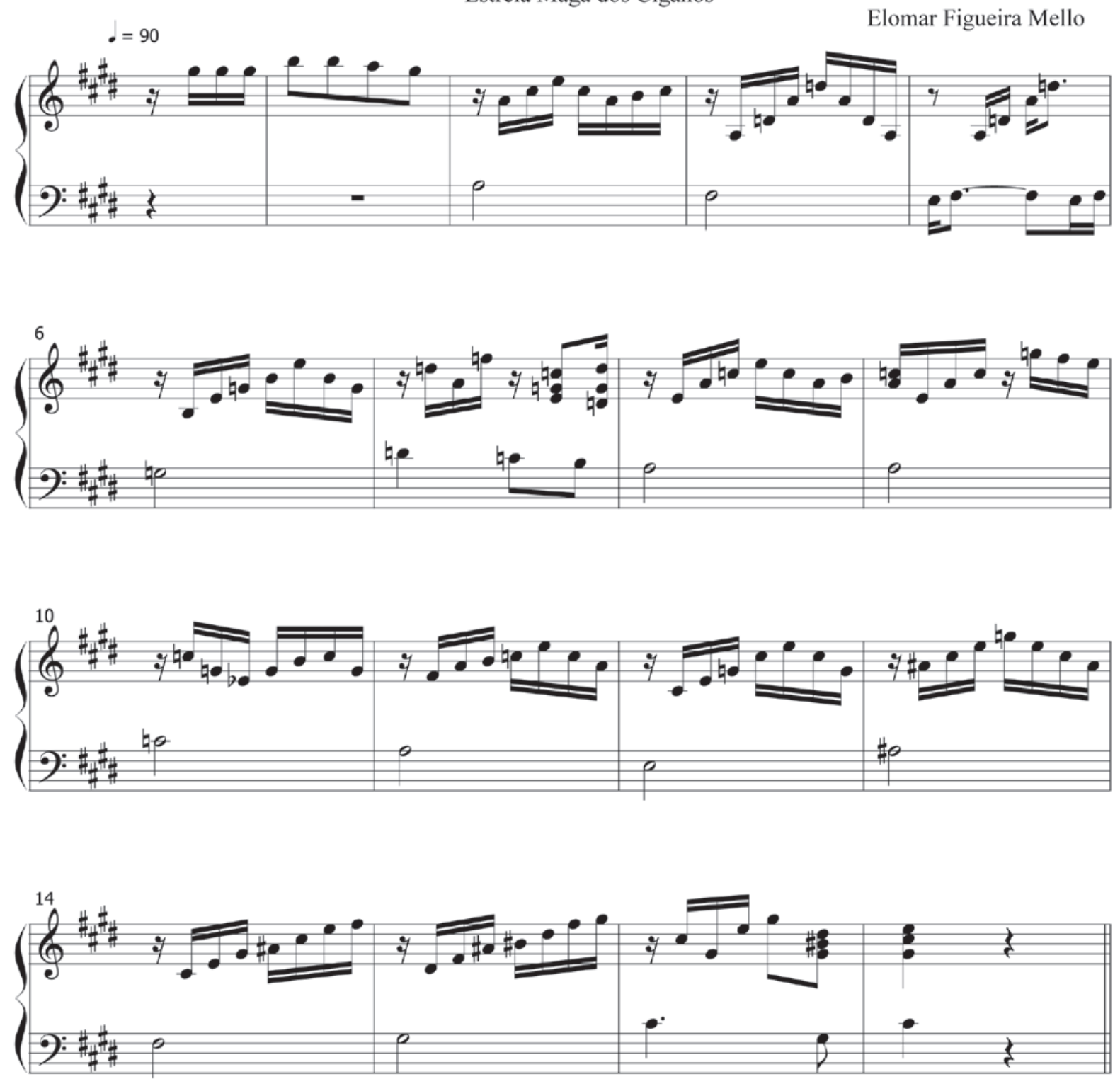

Trasncrição: Eduardo Ribeiro

Ex.2 - Estrela Maga dos Ciganos de Elomar Figueira Mello (Elomar: cancioneiro, Caderno n.10) 
evocando memórias antigas. 0 fraseado alterna a quadratura regular nos c.375-378 ("caixinha de música" com sininhos) com a "trupelada" (memórias turbulentas) nos c.381-386 (fraseado expandido, 4+2).
Poucos compositores conseguiriam colocar em xeque de forma tão contundente as tradicionais classificações de "música popular" e "música erudita". No cancioneiro, a estruturação harmônica e fraseológica de Elomar

Cena de Espancamento na Paulista da ópera "O Retirante" - excerto

Elomar Figueira Mello

373 barítono

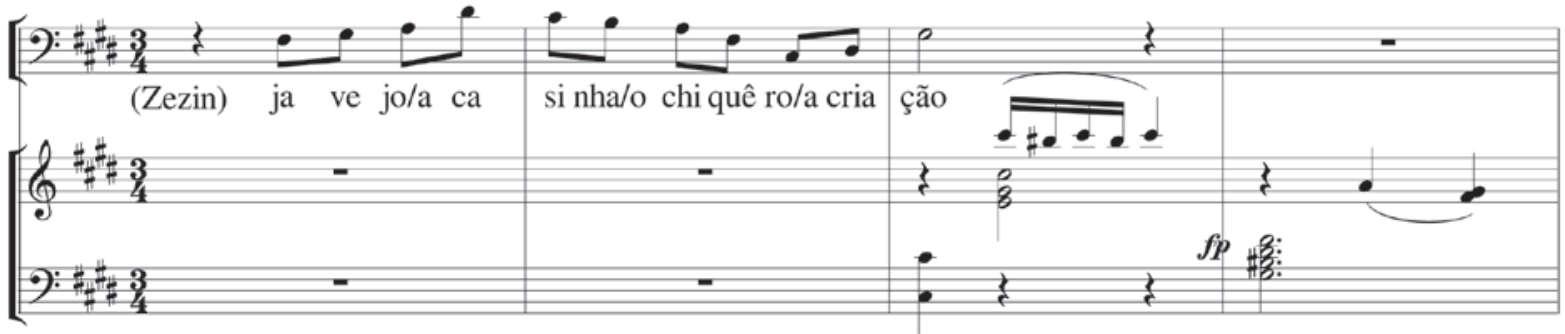

377

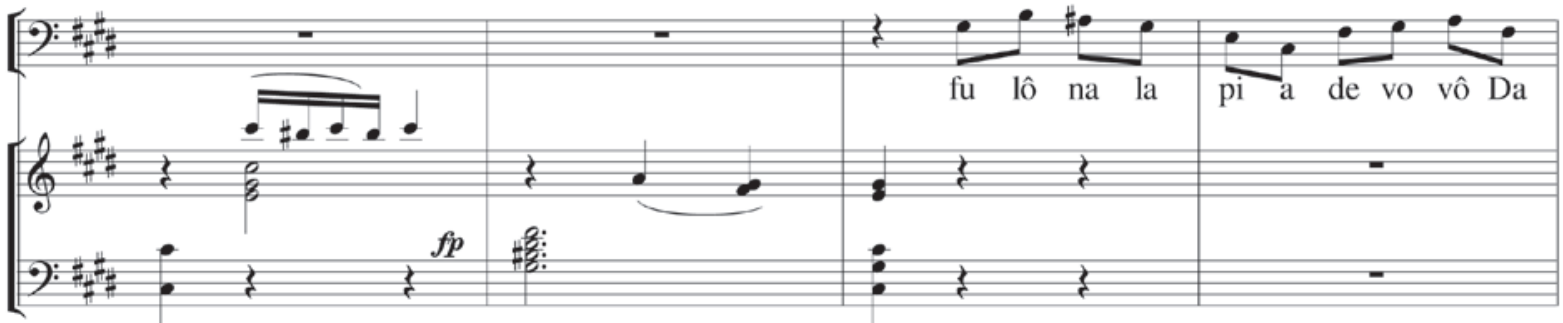

381
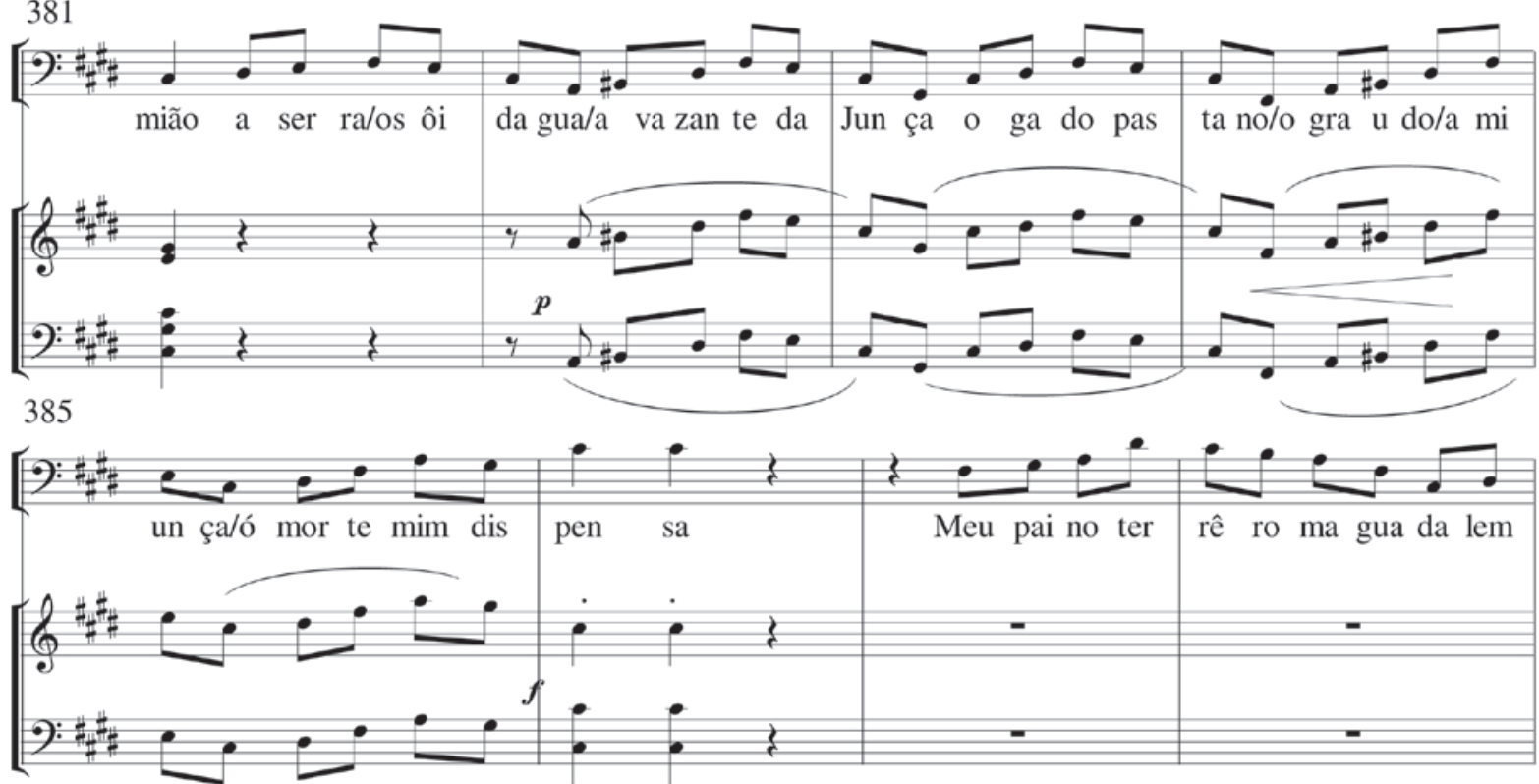

389

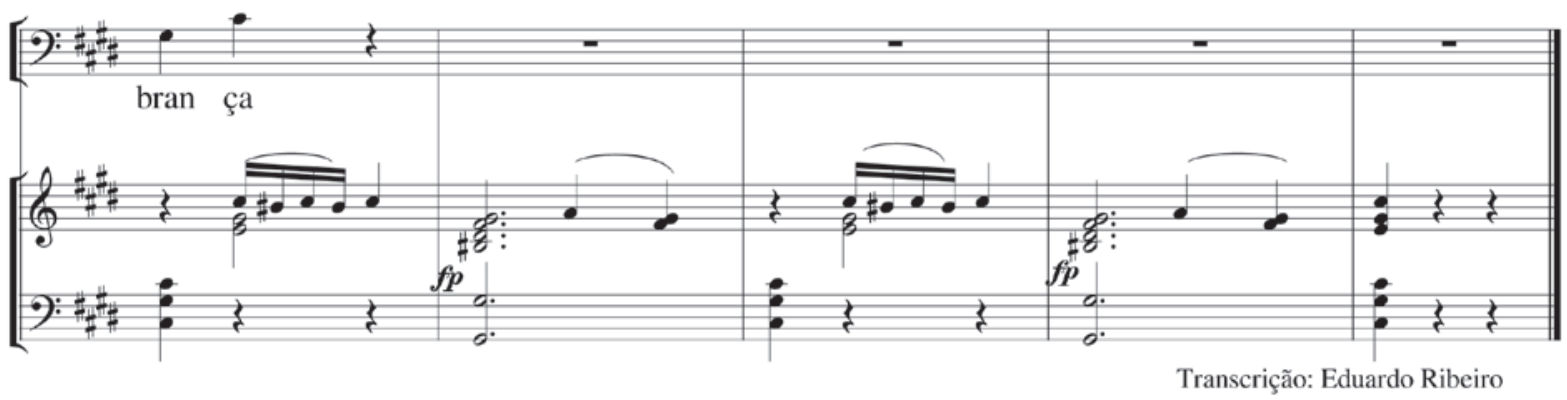

Ex.3 - Excerto da Cena de Espancamento na Paulista (ópera O Retirante de Elomar Figueira Mello). 
surpreende pela complexidade e em suas óperas, procedimentos semelhantes são aplicados a grandes formas com admirável maestria e efeito dramático.

A força expressiva da música de Elomar tem origem na conexão visceral com seu contexto cultural e com a preservação de traços arcaicos da cultura do sertão baiano, através dos gêneros tradicionais por ele trabalhados (tiranas, parcelas, cantoria nordestina, causos, aboios, entre outros).

As óperas de Elomar Figueira Mello, tal como as canções do cancioneiro apresentam abrangente variedade de traços hibridizados em um discurso de considerável riqueza musical, linguística e cultural. É significativo o uso frequente dos dialetos regionais, atitude coerente com a temática sertaneza ${ }^{4}$, e 0 universo de tópicos e sonoridades vocais a eles associados. Marcante é a hibridização entre o gênero lírico operístico e o canto sertanez, criando insólitos contextos dramáticos. 0 mesmo ocorre com as formas da cantoria regional tradicional, reelaboradas por Elomar em seu cancioneiro e as formas literárias por ele utilizadas cuja mescla gerou soluções de grande qualidade estética. Elomar revela ainda um domínio magistral na elaboração de uma dramaturgia sertaneza brasileira, original em muitos $a^{2}$ pectos ${ }^{5}$ e oferece consideráveis desafios aos cantores líricos, exigindo novas formas de impostação e emissão vocal para a compreensão adequada do dialeto.

0 estilo operístico de Elomar surgiu naturalmente em decorrência de seu trabalho compositivo no cancioneiro. Em suas canções e óperas, encontramos audácias harmônicas de desafiante complexidade estruturadas preferencialmente em ambientação modal com muitas interferências cromáticas, criando mesclas com o tonalismo.

Elomar desenvolveu seu conhecimento musical basicamente como autodidata. Teve mestres de violão na juventude e uma pequena passagem pela Universidade Livre da Bahia, criada por Koellreutter e Widmer. Em sua busca solitária por conhecimento debruçou-se sobre partituras, aprendeu orquestração e estruturação formal enquanto elaborava seu estilo compondo canções, árias e óperas. Conhecer a obra de Elomar, buscar suas origens estéticas e sua relação com a formação da música brasileira é uma aventura formidável em um universo de profunda riqueza artística e cultural.

\section{2 - 0 contexto da obra de Elomar}

"O que é meu discurso? Meu discurso consta de cantar uma realidade que me circunstancia, densa, amarga, às vezes trágica, mas com um sonhar, com uma proposta de sonhar, de esperança. No final, vencer a batalha"6. Elomar

Elomar nasceu em 1937 na Fazenda Boa Vista, na cidade de Vitória da Conquista (BA). Em sua infância no sertão ${ }^{7}$ ouviu cantadores, violeiros e repentistas tradicionais, absorvendo formas arcaicas do cancioneiro do sertão baiano com suas histórias e vivências - sua primeira e mais profunda influência estética. As palavras do próprio Elomar revelam aspectos de suas experiências musicais na infância:

[...] eu vi esses menestréis, eu vi aquela música singela ali do campo, os forrós, tocando na sanfona, no violão. Aqueles cantares rústicos, aquelas canções, aquelas modinhas, aqueles romances medievais já bem distorcidos semanticamente pelo passar dos séculos, não é? Roubo de donzelas... Ouvi Zé Crau, Zé Guelê cantar, não foram muitos não! Zé Tocador lá na região da Palmeira onde eu passei parte da minha infância. [...] Aos 7, 8 anos já ouvia Luís Gonzaga, Humberto Teixeira, essas coisas, aquele sucesso que tava. E no rádio ouvindo as serestas, a música seresteira brasileira: Chico Alves, Orlando Silva, Augusto Calheiros, Vicente Celestino e Carlos Galhardo, cantando esse cancioneiro da seresta, né? Tangos de Gardel, muitos [...] aos 15 anos eu fui prá Salvador estudar. Lá descobri a Protofonia do Guarani, Hora do Brasil"8.

Suas palavras revelam parte substancial das influências recebidas em sua formação musical na infância. Podemos também observar nesse leque de artistas e estilos ouvidos alguns dos elementos heterogêneos que explicam 0 hibridismo percebido em sua obra. Com Zé Crau, Zé Guelê e Zé Tocador, temos os cantadores tradicionais, representantes do estilo sertanez; com Luís Gonzaga, Humberto Teixeira e Zé do Norte ${ }^{9}$, o estilo urbano da música sertaneza inaugurado com a era das gravações; com Chico Alves, Orlando Silva, Augusto Calheiros, Vicente Celestino e Carlos Galhardo, o estilo seresteiro ${ }^{10}$; com Gardel, o tango argentino; e por fim, Carlos Gomes, com a Protofonia da ópera 0 Guarani e o estilo sinfônico erudito"11.

Embora envolto em sonoridades e formas roçalianas ${ }^{12}$, a curiosidade de Elomar se enveredou por estilos e gêneros diferentes dos praticados em seu contexto vivencial na infância e adolescência (como a Protofonia da ópera 0 Guarani). Desde tenra idade Elomar se interessou pela música orquestral erudita e em seus estudos se embrenhou em uma constante busca de mais conhecimento sobre a música orquestral e sobre a ópera.

Elomar é de família ligada à religião protestante, donde surge outro traço de caráter erudito em sua linguagem - o hinário protestante: "[...] ouvi desde criancinha, o hinarium da igreja Batista. Ali tem músicas de Bach, Haydn." (BASTOS, 2006, p.161) ${ }^{13}$. A influência dos hinários pode ser percebida em suas antífonas e em diversas passagens das óperas.

Para compreender em profundidade o discurso da obra de Elomar devemos considerar também as influências não musicais em seu estilo: o conhecimento das histórias seculares contadas através de várias gerações, a literatura de cordel, os "causos" e o modo de vida do sertão com sua simplicidade, envolvendo valores éticos como o compromisso com a palavra, a fé cristã, as tradições, festejos, mitos e lendas. Para Elomar são vivências praticamente extintas da vida no sertão de hoje, coisas que se perderam no mundo moderno, onde até mesmo locais mais distantes da urbe foram invadidos pela cultura de massa, principalmente através da televisão. Atualmente 
Elomar reside na fazenda "Casa dos Carneiros" no interior do sertão, com sua criação de bodes e carneiros, distanciado da vida conturbada da cidade como um "retirante" do mundo urbano ou um "anti-retirante".

Na adolescência, Elomar continuou os estudos secundários em Salvador e posteriormente formou-se em arquitetura, profissão que ainda exerce ocasionalmente ${ }^{14}$. Estudou violão clássico com a professora Edyr Cajueiro ${ }^{15}$ entrando em contato com obras do periodo renascentista europeu ${ }^{16}$. Seu conhecimento de compositores renascentistas incorporou traços do modalismo arcaico em sua linguagem musical. Algumas passagens e cadências modais nas Fantasias para vihuela de Luys de Milan ${ }^{17}$ soam familiares ao estilo de Elomar, o que sinaliza uma possível absorção desses traços em seu estilo. Nesse periodo de formação aproximou-se do estilo flamenco incorporando alguns de seus traços característicos como a cadência andaluza, o rasgueado e 0 uso do capotraste ${ }^{18}$. A esmerada técnica violonística e 0 estilo de execução de Elomar são traços importantes em sua linguagem, refletindo-se inclusive na escrita orquestral que mostra em certas passagens típicos padrões violonísticos adaptados a instrumentos orquestrais.

Elomar frequentou por alguns meses, aulas na Universidade Livre da Bahia fundada por Widmer e Koellreutter. Segundo ele tiveram pouca influência em sua formação, pois a linguagem do dodecafonismo não Ihe interessou, assim como as demais aulas na Universidade Livre da Bahia. No entanto, passagens dissonantes revelam traços composicionais que podem ter origem nessa curta experiência com Widmer e Koellreutter ${ }^{19}$.

A década de 70 marcou seu início de carreira como menestrel peregrino, tornando-se conhecido através de gravações comerciais e de inúmeros concertos realizados no pais e exterior. 0 cancioneiro, a parte mais conhecida de sua obra, está registrado em diversos álbuns, o primeiro datado de $1973^{20}$ e o último (até o momento), gravado em $1992^{21}$, totalizando 16 diferentes títulos comerciais.

Seu cancioneiro nos mostra uma forma de elaboração do fraseado que, entre outros traços, diferencia sua obra de qualquer outra produzida no país. Um desses traços, intimamente conectado com a prosódia roçaliana, é a aceleração rítmica da linha cantada em palavras que excedem a métrica. Ivan Vilela, em tese de doutorado sobre a música caipira afirma ${ }^{22}$ :

\footnotetext{
"Talvez não pela importância dada ao uso das regras de metrificação, algumas vezes os versos se fazem maiores que 0 tamanho da melodia que os comporta. A saída para lidar com este aparente problema é um acelerar da fala que extrapola o esperado rítmico, criando assim um novo e sofisticado recurso, o da transgressão da normalidade prosódica." (VILELA, 2011, p.50) ${ }^{23}$.
}

Esse traço explica em parte as quebras de quadratura e irregularidades fraseológicas, características do estilo de Elomar. Na estruturação de suas canções, danças e árias, utiliza com frequência extensões e contrações de quadraturas, recurso que normalmente é associado a passos harmônicos modalizantes e frequentes cromatismos, dinamizando seu discurso musical.

Sua primeira obra caracterizada como ópera surge em 1969 - o Auto da Catingueira ${ }^{24}$ - obra na qual Elomar já mostra sua verve lírica, dramática e trágica em um discurso musical consideravelmente complexo, ultrapassando os limites estéticos do gênero "Auto". Sobre esta obra encontramos dezenas de referências em títulos acadêmicos que investigam a riqueza e a pluralidade de seu discurso. Sua primeira incursão na composição do gênero cênico-musical, o Auto da Catingueira representa o nascimento do estilo operístico elomariano.

A partir de 1984, Elomar conclui a obra por ele chamada de cancioneiro, dedicando-se cada vez mais à composição e realização de óperas. São elas: $A$ Carta, ópera em quatro cenas; $O$ Retirante, ópera com um prólogo e dois atos; Faviela; O Peão Mansador; A Casa das Bonecas; dentre outras. Além de óperas, outros gêneros sinfônicos foram utilizados por Elomar: Galope Estradeiro (pequena sinfonia em 3 movimentos), Concerto para violão e orquestra, 11 Antifonas para solistas, coro e orquestra e outras obras menores. Em outubro de 2004, no Teatro Nacional de Brasília ocorreu a $1^{\text {a }}$ apresentação integral de uma de suas óperas, A Carta, obra pertencente à "pentalogia"25 Bespas Esponsais Sertana - 5 pequenas óperas trágicas, sob a regência do maestro Henrique Morelenbaum ${ }^{26}$.

Elomar prefere viver afastado do mundo urbano se ocupando principalmente da composição e da criação de bodes e carneiros. Para encontrá-lo é necessário viajar alguns quilômetros adentrando o sertão baiano em estradas de terra batida. A tradicional visão dos leitos secos dos riachos, vegetação de caatinga, ossadas de animais e urubus já prenuncia alguns traços de seu complexo discurso estético.

Contudo, o envolvimento com a divulgação da ópera brasileira ocupa grande parte de seu tempo atual obrigando-o a manter contato constante com a urbe. Elomar é um artista entusiasmado e luta pela conquista de apoio e reconhecimento pelo seu trabalho, mas não deixa de expressar sua desilusão com o estado atual da cultura brasileira e mundial.

Segundo ele, sua obra e também sua própria pessoa, não são outra coisa senão "antagônicos-dissidentes irrecuperáveis de sua contemporaneidade"27 tendo em vista sua formação erudita e regionalista (tanto no aspecto literário quanto no musical) e o autodidatismo, que coloca sua obra em um espaço entre a música popular e a erudita, tornando-a às vezes difícil de ser classificada e de ser compreendida. A arte de Elomar exige a atenção, a inteligência e o coração - não é apta ao consumo, não é "entertainment" e não é propriamente popular ${ }^{28}$. É parte de um elo secular de tradições e convergências estéticas, em uma linhagem romanesca a representar menestréis, trovadores, repentistas, cordelistas, oradores, escritores e pregoeiros do Brasil. 


\section{3 - Arte para o povo e para o intelectual}

A linguagem elomariana mesmo nas óperas é compreensivel primordialmente pelo habitante do sertão. Para a cultura roçaliana o entendimento de uma ópera de Mozart ou Verdi se ressentiria pela falta de vivência dos gêneros europeus ${ }^{29}$, mas o dialeto associado ao canto lírico e os temas tradicionais do cotidiano sertanez cantam no berço de sua cultura e são prontamente absorvidos pelos habitantes do sertão: lavradores, lavadeiras, agricultores, vaqueiros, crianças, donas de casa ouvem a música de Elomar e são capazes de reconhecer gêneros familiares entretecidos entre outros desconhecidos, se encantando nessa experiência estética. Elomar também integra gêneros urbanos em seu discurso, representando o urbanoide ${ }^{30}$, o intelectual e o poder instituído.

A linguagem musical de Elomar é desenvolvida a partir de traços da musicalidade popular regional e podemos reconhecer em sua obra traços objetivos dessa "prosaística" 31 composicional na forma com que tece em seu discurso uma profusão de gêneros: cantoria nordestina, serestas, hinário evangélico, estilo flamenco e modalismo renascentista, reelaborados em uma linguagem erudita e complexa.

Não podemos deixar de considerar o uso extensivo e consciente do dialeto em toda sua obra, servindo como recurso distintivo na caracterização da origem social e/ou geográfica dos personagens. Em suas óperas, Elomar distingue cuidadosamente os tipos urbanos dos sertanezes. Os urbanos sempre falam (cantam) em vernáculo (e eventualmente gíria, anglicismos, francesismos, latinismos e/ou modernismos) e merecem tratamento fraseológico adequado à prosódia diferenciada entre o português comum e o dialeto falado pelos roçalianos. Os processos de elaboração e articulação formal de suas extensas árias, nas quais ocorre uma efervescente fusão de gêneros (roçalianos, urbanos e europeus) são suficientes para a percepção da erudição e largueza estética das óperas de Elomar. Poderíamos nos arriscar a dizer, no entanto, que a essência de seu denso discurso é comprendida de maneira natural pelos habitantes do sertão, em virtude do dialeto e dos gêneros roçalianos, e surpreende 0 ouvinte urbano intelectualizado pela sua potencialidade, pela intensidade dramática, pelo primor formal e pela harmonia dialógica entre os recursos musicais e literários utilizados. A "forma" em Elomar se distingue pela rica e imaginativa conjunção entre o conteúdo literário e os recursos miméticos de seu ideário musical: o domínio da melodia e harmonia, da prosódia dialetal e dos gêneros roçalianos, urbanos e eruditos.

Os libretos de suas óperas, todos de sua própria autoria, são considerados grande poesia pela riqueza com que maneja a língua vernácula e o dialeto com suas variações, assim como pelo resgate das histórias e da cultura sertaneza em vias de extinção.
Encontramos uma rica paleta de gêneros discursivos na construção do estilo elomariano: a tradição da cantoria nordestina, os hinários evangélicos, o estudo do violão clássico, a busca autodidata de conhecimento orquestral e operístico, a literatura e a própria vida no sertão a inspirar e trazer conteudos vivos para a construção de seu discurso musical. 0 estudo da trajetória musical elomariana permite a compreensão da íntima relação entre processos composicionais e vivenciais, atribuindo uma profunda dimensão de significado social ao seu universo estético. Elomar é um músico que tem muito a ensinar com sua praxis musical autêntica e responsável em relação a seu contexto de origem, o sertão do sul da Bahia.

Elomar surpreende-nos também com concepções estéticas originais para o entendimento de sua obra, fornecendo aos estudiosos elementos importantes para a compreensão de seu discurso como um todo. Elomar fala de dois sertões, um geográfico e político, o "sertão oficial", e outro, transcendente e onírico, o "sertão profundo". Através da ideia de "sertão profundo" Elomar dimensiona sua estética na atemporalidade, onde convivem elementos da cultura clássica e da cultura nordestina, conforme explica GUERREIRO (2007):

\begin{abstract}
"De modo genérico, são dois os sertões por onde estradeiam os personagens elomarianos. Dois os mundos ali inseridos: o sensível - 'sertão-de-fora' - e o intangível: 'sertão profundo/ sertão-de-dentro'. Por um lado, o sensivel compreende-se pelo desdobrar de um sertão clássico - no qual valores éticos e morais conferiam tônica de respeitabilidade e convivência - ao sertão contemporâneo: 'sertão da desconsideração, da indigência' [...] o sertão profundo: alocação ideal para onde o autor envia os personagens de modo a recuperar, por eles, exatamente os valores perdidos de um sertão clássico, arcaico. Trata-se portanto, de um sertão transcendente 'inserido na geografia política do sertão', insólito, só existindo em 'estado de espírito inventivo' onde reinam a palavra e o exercício medido e conformado à Lei de Deus." (grifos do autor) (Entrevista a Elomar. GUERREIRO, 2007)
\end{abstract}

Elomar explica sua concepção estética com admirável clareza, ao falar da temática medieval em suas obras: "[...] eu vou pegar um sertão lá longe, que deve ter havido nos tempos da Idade Média, ou melhor, dentro do período feudal, que tinha um sertão semelhante a esse sertão profundo que eu tenho proposto". (ROSSONI, 2007, p.3).

\section{4 - Temática da música e poesia de Elomar}

Em Cultura e Identidade nos sertões do Brasi ${ }^{32}$, ALENCAR (s.d.) classifica os temas típicos na literatura relativa ao sertão. Segundo o autor, encontramos:

"[...] temas recorrentes, que podem ser reunidos em seis grandes grupos, girando em torno do cotidiano da vida rural ou da nostalgia do exílio: Natureza: terra, rios, água, céu, estações do ano, sol, chuva, vento, peixes, aves, o gado. Festa: viola, cachaça, congraçamento entre companheiros. Folclore: animais do folclore regional. Amor: amor romântico, idealização da mulher. Religiosidade: romarias, santos da devoção popular. Questões sociais: liberdade, fome, seca, luta pela terra, retirantes, ecologia". (grifos nossos) (p.10).

A temática associada à obra elomariana está aí em grande parte representada, mas poderíamos acrescentar alguns típicos temas elomarianos como: celebração de bodas, vida 
dos ciganos, a solidão do vaqueiro, os mistérios (visages, latumias, assombrações), os desafios e duelos de morte e muitos outros. 0 estilo de Elomar se desenvolve a partir dessa temática em um processo de transformação dos gêneros tradicionais da cantoria nordestina, das modas de viola e outros estilos (cancioneiros medievais, flamenco, tango, seresta) em obras pertencentes a gêneros eruditos, como a ópera, o recitativo e ária, a sinfonia e o concerto.

Elomar e sua obra surgem como um marco significativo e uma espécie de síntese dentro do panorama da música popular brasileira, oferecendo um novo paradigma para a música erudita brasileira. Sua obra veicula discursos com conexões de ampliada temporalidade através da herança arcaica ibérica com suas formas musicais, formas de tocar, utilização de escalas e cadências e também da temática dos romanceiros. Também traz marcas do gregoriano pela incorporação dos desafios e da cantoria nordestina como um todo. Seu cancioneiro e suas óperas são enciclopédias de gêneros da cantoria nordestina e dialogam fluentemente com gêneros andaluzes e o flamenco. A modinha, o lundu e a seresta, gêneros através dos quais Elomar expande sua paleta expressiva em suas árias operísticas, encontram tratamento bastante variado e podemos perceber diálogos entre o hinário cristão tradicional evangélico e esses gêneros.

As danças tradicionais representam uma importante parcela de componentes em sua obra, enriquecendo seu discurso com uma profusão de gêneros: são as danças brasileiras folclóricas rurais e urbanas, nas quais se incluem as danças europeias modinhizadas e lundunhizadas (polcas, marchas, contradanças, schottisches, etc), danças barrocas, danças do carnaval, choro, samba, enfim, as festas e folguedos sertanezes com sua música religiosa e secular. Esses elementos - heranças modinholundunheiras, danças estrangeiras e nacionais, o hinário cristão, a herança ibérica nas cadências, escalas e toques, a cantoria nordestina e a música urbana de uma época pré-manipulada pela marqueteria encontram no estilo de Elomar o campo de diálogo com o paradigma sinfônico europeu e principalmente com a ópera europeia e o canto lírico. Elomar alça os gêneros primários anteriormente descritos ao patamar das grandes estruturas discursivas através da elaboração de tópicos literários, poéticos e religiosos como a épica, a epopeia, a epifania e a lírica (as odes, elegias, canções de gesta, canções de escárnio, etc.).
A obra de Elomar permite o diálogo amplo entre gêneros que permeiam a construção do universo sonoro brasileiro, gêneros esses situados à margem das influências mercadológicas e praticamente banidos do circuito cultural. 0 Corpus Elomarianum transita em um universo complexo de tópicos musicais, literário-poéticos, religiosos, moralizantes, históricos, filosóficos, geográficos, políticos e sociais. 0 estilo elomariano é inseparável da própria figura de Elomar, sua voz, seu estilo de tocar violão e suas ideias, e em especial, da comunidade surgida a seu redor, a "Escola Elomariana", também conhecida por "Nova Cantoria" da qual fazem parte Xangai, Dércio Marques, Rubinho do Vale, Paulinho Pedra Azul, e muitos outros que encontram inspiração em sua arte. 0 estilo de Elomar implica uma tomada de posição perante o mundo e não se pauta por escolhas estéticas, pelo contrário, suas escolhas estéticas são pautadas pela necessidade de expressão de sua visão do mundo.

Paradoxalmente, Elomar vive em parte na urbe, na cidade poluída e cheia de automóveis, dirige sua caminhonete e usa "internet". Mas, sábio como é, vive nos dois mundos de olhos abertos, sua produtora lida com a "interface urbe-sertão" que é inevitável em seu caso, preservando-o do embate com o cotidiano urbano. Nessa atitude e praxis perante a cidade e o campo, podemos compreender como o estilo de vida de Elomar é conguente, apesar dos paradoxos aparentes em sua obra e sua visão de mundo.

Em relação à ópera nacional, Elomar traz um novo estilo, ainda desconhecido da maioria dos músicos e público, e batalha constantemente por condições para produzir suas óperas. Simões (2006) $)^{33}$ diz sobre a proposta de Elomar para ópera nacional:

\footnotetext{
"Elomar atualiza a ópera brasileira ao Ihe dar o colorido linguístico, característico da cultura nela retratada. Fala, ao mesmo tempo com o homem que vive e presencia as vicissitudes do Nordeste e como o artista que se distancia do mundo para poder transformálo em puro gozo estético". (SIMÕES, 2006, p.57-58).
}

Elomar é um artista de grande estatura, tanto no gênero popular como no erudito e conhecer sua obra é fundamental para o aprofundamento das investigações sobre as raízes da música brasileira. 0 estudo de sua obra traz à tona elos perdidos na formação de nossa musicalidade através da riqueza multifacética de seu estilo e da resignificação do milenar embate popular X erudito. 


\section{Referências}

ALENCAR, Maria Amélia Garcia de. Cultura e Identidade nos sertões do Brasil - Actas del III Congresso Latinamericano de la Associacion Internacional para el Estudio de la Música Popular - http://www.hist.puc.cl/historia/iaspmia.html, s.d.

BASTOS, Eduardo Cavalcanti. Nova Cantoria:Movimento Poético-Musical de Elomar Figueira Mello, Dércio Marques e Xangai. Salvador: UFBa, 2006 (Tese de Doutorado).

CARVALHO MELLO, João Omar de. Variações motívicas como princípio formativo: uma abordagem fraseológica sobre a obra Dança de Ferrão, para violão, flauta e pequena orquestra, do compositor Elomar Figueira Mello. Salvador: Escola de Música da UFBA, 2002 (Dissertação de Mestrado).

CUNHA, João Paulo. Elomar: cancioneiro. Belo Horizonte: Duo Editorial, 2008.

GUERREIRO, Simone. Tramas do Sagrado: a poética do sertão de Elomar. Salvador: Editora Vento Leste, 2007.

MICHAELIS. Moderno Dicionário da Língua Portuguesa. Ed. Melhoramentos, 1998.

MILAN, Luys. El Maestro. Vol.1. Composizioni per sola vihuela. Transcrizione in notazione moderna per chitarra di Ruggero Chiesa. Milano: Edizioni Suvini-Zerboni, 1965.

MORSON, Gary Saul \& Emerson, Caryl. Mikhail Bakhtin, Criação de uma Prosaística.. São Paulo: EDUSP, 2008.

RIBEIRO, Eduardo de Carvalho. Os Gêneros do Discurso na Obra Operistica de Elomar Figueira Mello, uma abordagem bakhtiniana. Belo Horizonte: EMUFMG, 2011 (Dissertação de Mestrado).

ROSSONI, Igor. Do trágico ao fantástico em Auto da Catingueira de Elomar Figueira Mello. Salvador: Departamento de Fundamentos para o Estudo das Letras da UFBA, 2007.

SIMÕES, Darcília (org.); Luiz Karol \& Any Cristina Salomão. Língua e Estilo de Elomar. Publicações Dialogarts. Rio de Janeiro, 2006.

VILELA, Ivan Pinto. Cantando a própria história. São Paulo: Instituto de Psicologia da Universidade de São Paulo, 2011 (Tese de Doutorado).

\section{Discografia}

MELLO, Elomar Figueira. O Violeiro e a Canção da Catingueira. Compacto simples, 1968.

.Das Barrancas do Rio Gavião. São Paulo: Polygram, 1973.

.Na Quadrada das Águas Perdidas. Gravadora Rio do Gavião e Discos Marcus Pereira, 1978.

.Parcelada Malunga. Com LIMA, Arthur Moreira; DO MONTE, Heraldo; GOMES, José; XANGAI. Gravadora Rio do

Gavião e Discos Marcus Pereira, 1980.

.Fantasia Leiga para um Rio Seco. Orquestração e regência: Lindemberg Cardoso. Gravadora Rio do Gavião, 1981. .ConSertão. Com LIMA, Arthur Moreira; MOURA, Paulo; DO MONTE, Heraldo. Rio de Janeiro: Kuarup Discos, 1982. .Cartas Catingueiras. Gravado em Setembro de 1982, no Nosso Estúdio - São Paulo: Gravadora Rio do Gavião, 1983. .Cantiga do Boi Encantado. In: WIDMER, Ernst. Sertania: Sinfonia do Sertão. Salvador: FCEBA, 1983.

.Auto da Catingueira. Gravado na Casa dos Carneiros, 1983. Gravadora Rio do Gavião, 1984.

.Cantoria 1. Com AZEVEDO, Geraldo; FARIAS, Vital; XANGAI. Rio de Janeiro: Kuarup Discos, 1984.

.Cantoria 2. Rio de Janeiro: Kuarup Discos, 1984.

.Dos Confins do Sertão. Gravado ao vivo no Festival de Música Ibero-americana-Alemanha. Alemanha Ocidental:

Trikont, 1986.

. Concerto Sertanez. Com SANTOS, Turíbio; XANGAI e participação de João Omar. Gravado ao vivo no Teatro Castro Alves em Salvador. Rio de Janeiro: Estúdio de Invenções, 1988.

.Elomar em Concerto. Com Quarteto Bessler-Reis, Paulo Sérgio Santos, Marcelo Bernardes, Antônio Augusto e Octeto Coral de Muri Costa. Regência e Direção Musical de Jacques Morelenbaum. Gravado ao Vivo na Sala Cecília Meireles. Rio de Janeiro: Kuarup Discos, 1989.

.Árias Sertânicas. Participação de João Omar. Gravadora Rio do Gavião, 1992.

Cantoria 3, canto e solo. Gravado ao Vivo no Teatro Castro Alves, Salvador, e no Palácio das Artes, em Belo Horizonte. Rio de Janeiro: Kuarup Discos, 1995.

XANGAI. Xangai canta cantigas, incelenças, puluxias e tiranas de Elomar. Convidados: Elomar e João Omar. Rio de Janeiro: Kuarup Discos, 1986.

\section{Notas}

1 A discografia de Elomar com 16 títulos pode ser consultada nas referências bibliográficas.

2 CUNHA, João Paulo. Elomar: cancioneiro. Belo Horizonte: Duo Editorial, 2008.

3 CARVALHO MELLO, João Omar de. Variações motívicas como princípio formativo: uma abordagem fraseológica sobre a obra Dança de Ferrão, para violão, flauta e pequena orquestra, do compositor Elomar Figueira Mello. Salvador: Escola de Música da UFBA, 2002 (Dissertação de mestrado); e RIBEIRO, Eduardo de Carvalho. Os Gêneros do Discurso na Obra Operística de Elomar Figueira Mello, uma abordagem bakhtiniana. Belo Horizonte: EMUFMG, 2011 (Dissertação de Mestrado). 
4 Sertanez: neologismo elomariano: originário do sertão, relativo ao sertão. Elomar contrapõe o termo "sertanez" a "sertanejo", no sentido de diferenciar o habitante autêntico do sertão, o sertanez, do habitante urbano de estilo cowboy com indumentária texana, chamado pela mídia de "sertanejo" assim como a "música sertaneja" que é difundida pela indústria cultural, gênero bastante distante do estilo de Elomar.

5 Em sua ópera A Carta, Elomar utilizou um raro recurso cênico-musical, com grande efeito dramático. Na Cena do Apartamento, o personagem "Plêiboi" (sic), um tenor, arma uma cilada para estuprar a jovem e bela "Maria". Na primeira parte da ária o personagem canta de forma sedutora, irônica e jovial, mas a jovem resiste firmemente ao seu convite, mas em certo momento é substituído em cena (recurso bastante raro!) por um baritono que canta a segunda parte da ária, o tenor não retorna mais. Uma passagem instrumental anuncia o momento em que o "Plêiboi" modifica suas intenções e decide colocar um dopante em uma taça de vinho oferecida à moça, criando um clima de crime e trapaça intensificado pela mudança de timbre e registro vocal. Um notável tratamento do corpo em cena e da voz no contexto operistico com novas abordagens dramáticas e psicológicas.

6 ROSSONI, Igor. Do trágico ao fantástico em Auto da Catingueira de Elomar Figueira Mello. Salvador: UFBa. Departamento de Fundamentos para o Estudo das Letras, p.32., 2007 (Entrevista).

7 "[...] sertão nordestino, o localizado na região sudoeste da Bahia - mais precisamente às fronteiras do Sertão da Ressaca a partir do Mato-Cipó com toda tradição de uma antropo-melografia ibérica, vincada por aproximadamente oito séculos de ocupação moura". (ROSSONI, 2007, p.1).

8 RIBEIRO, Eduardo de Carvalho. Elomar na Fazenda Casa dos Carneiros. Vitória da Conquista, Bahia: 29/07/2009 (Entrevista).

9 E mais Jackson do Pandeiro, também citado por Elomar.

10 E também Noel Rosa, Sílvio Caldas, Ary Barroso, Lupicinio Rodrigues e Mário Lago, dentre outros cancionistas famosos e divulgados através do rádio, ouvidos por Elomar no periodo vivido em Salvador.

11 VILELA (2011) afirma que "vários artistas quando famosos negam suas reais influências. Pat, Gismonti, Elomar. Se o ouvirmos, perceberemos a mais forte presença de Dorival Caymmi. A única concessão de Elomar a gravar músicas de outrem foi gravar Caymmi".

12 Roçaliano: neologismo criado por Elomar. Significa, aquilo que se relaciona ou se origina na cultura do interior, do campo ou "roça".

13 BASTOS, Eduardo Cavalcanti. Nova Cantoria: Movimento Poético-Musical de Elomar Figueira Mello, Dércio Marques e Xangai. Salvador: UFBA, 2006.

14 Em Vitória da Conquista diversos edifícios, templos e outras construções de grande porte foram projetados por Elomar, assim como o Domus Operae, teatro de ópera construido em 2010 na Fazenda "Casa dos Carneiros".

15 "Aos 18 anos era considerado concertista de violão clássico e executava composições de Villa Lobos, Enrique Granados, Joaquin Rodrigo e Francisco Tárrega. Permanece na carreira de concertista até os 25 anos." (BASTOS, 2006, p.93).

16 "Na cidade de Vitória da Conquista, amplia ainda mais a teia de conhecimentos, percorrendo vários saberes da história da música ocidental, passando a conhecer as peças escritas para instrumentos de cordas medievais como o alaúde ou vihuela, bem como autores renascentistas como Gaspar San, Robert de Visée e Luiz de Milan." (itálicos nossos) (BASTOS, 2006, p.91).

17 MILAN, Luys. El Maestro. Vol.1. Composizioni per sola vihuela. Transcrizione in notazione moderna per chitarra di Ruggero Chiesa. Milano: Edizioni Suvini-Zerboni, 1965

18 A cadência andaluza é baseada no tetracorde frígio (IV-III-II-I\#), com a terça maior ao final. A falsa relação produzida com o III grau é bastante caracteristica em Elomar, sendo praticada de forma semelhante em outros graus. Elomar também acrescenta dissonâncias nessa cadência (as notas de tensão) de maneira parecida ao estilo flamenco andaluz. 0 rasgueado é um estilo de execução, onde golpes com a ponta dos dedos (e unhas) tocam todas as cordas simultaneamente, com sonoridade forte e áspera, de caráter rítmico. 0 capotraste é um dispositivo que se coloca no braço do violão para transpor a tonalidade.

19 Como no final da cena Boca das Águas da ópera O Retirante e na cena A Leitura da Carta da ópera A Carta.

20 Das Barrancas do Rio Gavião. São Paulo: Polygram, 1973. Antes disso, em 1968, Elomar gravou um compacto simples: O Violeiro e a Canção da Catingueira.

21 Árias Sertânicas. Rio do Gavião, 1992.

22 VILELA, Ivan. Cantando a Própria História. São Paulo: USP, 2011 (Tese de Doutorado).

23 VILELA (2011) afirma: "Na realidade, essa é uma caracteristica transmitida oralmente e Elomar traz este traço forte da narrativa (romance) em sua obra. Isto acarreta uma caracteristica na sua música: o ritmo harmônico é particular, pois foge das incidências esperadas por estarem presas ao texto, à palavra".

240 Auto da Catingueira foi gravado na Casa dos Carneiros em 1983. Rio do Gavião, 1984.

25 Trata-se de um neologismo elomariano criado por analogia à "tetralogia".

te.tra.lo.gi.a. $s f\left(\right.$ tetra+logo $\left.{ }^{2}+i a^{1}\right) 1$ Conjunto de quatro peças teatrais que os poetas gregos apresentavam nos concursos, sendo três tragédias e um drama satírico ou burlesco. 2 Mús Conjunto de quatro óperas. (MICHAELIS Moderno Dicionário da Língua Portuguesa. Ed. Melhoramentos, 1998). Por analogia, "pentalogia" significa: conjunto de cinco óperas.

26 Outras óperas e composições eruditas de Elomar ainda esperam por apoio para sua produção. Elomar luta pela realização de suas óperas, para que, assim como tantos outros compositores brasileiros, não sejam perdidas no esquecimento. 0 motivo é bastante triste: a preferência dos teatros nacionais em executar prioritariamente, obras estrangeiras.

27 RIBEIRO, Eduardo de Carvalho. Elomar na Fazenda Casa dos Carneiros. Vitória da Conquista, Bahia: Fazenda Casa dos Carneiros, 29/07/2009 (Entrevista).

28 "Elomar [...] tem sua musicalidade sertaneza fundida com a música clássica, compondo assim um conjunto melódico e harmônico distinto de todas as criações musicais do cenário brasileiro, diferenciando-se sobretudo, do movimento poético-musical dos poetas-cantadores da Cantoria Nordestina." (BASTOS, 2006, p.90).

$29 \mathrm{E}$, obviamente, pelas dificuldades com a língua.

30 Urbanoide: maneira pejorativa com que Elomar identifica o homem urbano.

31 Prosaico (adj.): relativo ou pertencente à prosa; que tem a natureza da prosa. Que não tem elevação, que é comum, vulgar, rasteiro. Que não tem poesia, in: http://www.dicionarioweb.com.br/html. Bakhtin opõe o conceito de "prosaico" ao conceito de "poético", reabilitando o termo, de onde surge a palavra "prosaística", neologismo derivado da palavra "prosaico" como alternativa a "poético". As implicações deste novo conceito são discutidas no livro: Mikhail Bakhtin, Criação de uma Prosaística. Morson, Gary Saul \& Emerson, Caryl. São Paulo: EDUSP, 2008.

32 ALENCAR, Maria Amélia Garcia de. Cultura e Identidade nos sertões do Brasil - Actas del III Congresso Latinamericano de la Associacion Internacional para el Estudio de la Música Popular, s.d., in: http://www.hist.puc.cl/historia/iaspmia.html.

33 SIMÕES, Darcília (org.); Luiz Karol \& Any Cristina Salomão. Lingua e Estilo de Elomar. Publicações Dialogarts. Rio de Janeiro, 2006.

Eduardo de Carvalho Ribeiro é Bacharel em Composição e Regência (UFMG) e mestre em Musicologia (UFMG). Atualmente é professor do Departamento de Teoria Geral da Música na Escola de Música da Universidade Federal de Minas Gerais (UFMG) em Belo Horizonte, onde ministra aulas de Harmonia, Análise e Composição. Suas pesquisas envolvem a semântica musical, a música colonial e erudita brasileira, a obra de Elomar Figueira Mello e a música barroca europeia. 